\title{
Obsessive Thinking
}

National Cancer Institute

\section{Source}

National Cancer Institute. Obsessive Thinking. NCI Thesaurus. Code C117285.

A series of thoughts that are difficult to suppress and may be a consequence or cause of anxiety. 